\title{
On the Important Connotation of First - class Undergraduate Education is "Double -first-class" Construction
}

\author{
Jing Liu \\ Tonghua Normal University, Tonghua Jilin, 134001, China
}

Key words: First-class undergraduate universities, Double first-class, Discussion.

\begin{abstract}
Undergraduate education is an important foundation of building first-class universities and developing first-class disciplines. Therefore, colleges and universities should make the education concept be updated, and the reform and innovation must be carried out in the aspect of personnel training, and must be innovated in the governance structure and management system of teaching, to create a campus culture, teaching atmosphere, so as to make our first-class undergraduate education construction meaningful. Therefore, this article mainly for "double first-class" undergraduate education, based on foreign lessons from the past, pay attention to ideas, refining the basic model elements.
\end{abstract}

\section{Introduction}

Since China's "211 Project" "958 project" in practice after the implementation of China's higher education also will gradually increase in the international influence. In addition, in order to build a world-class university and first-class disciplines of the guiding ideology, basic principles, overall objectives, construction and reform, should be more clear support measures and organization and implementation, in the implementation of thoroughly implemented. The State Council in October 2015 released the "co-ordination of world-class universities and first-class discipline construction of the overall program", so that institutions can further stimulate the impact of world-class construction enthusiasm. The improvement and deepening of the program was carried out on the basis of implementing the "211 Project" and "985 Project" in the middle and late 1990s, and it is an important measure and inevitable choice for the construction of higher education power and the realization of human resources and other strategies [1]. Moreover, after the promulgation of the program, not only in the colleges and universities caused a high degree of attention, while in the community also caused a great response. In addition, to make the work of colleges and universities in the construction of world-class universities and first-class discipline development ("double first-class" construction work can be smooth, then for its own connotation construction, comprehensive reform must be rigorous and deep grasp, breaking the traditional school philosophy, Personnel training and discipline, team, culture and other construction, fundamentally improve the quality and level of undergraduate education, and then stand a new perspective on the "double first-class" construction work.

\section{The Reason for Emphasizing Undergraduate Education}

With the development of the times, for people, education is an integral part of life, so it also shows the importance of education. At present, colleges and universities in addition to the traditional functions of several functions, but also need to bear it's political, economic, cultural, livelihood, employment, stability and other social responsibility, which also led to the pressure on their weight. With the increasing demand for social diversification, colleges and universities are also keeping up with the pace, the size of the school is also growing [2]. However, although the scale of running a school, but failed to the so-called "good university standards" - paper-oriented, project-first and other issues a 
perfect solution, resulting in undergraduate teaching has been ignored, the role of higher education for the perfect play by a certain influences.

\section{The primary responsibility of higher education is to cultivate talents}

For example, talent training, scientific research, social service, cultural heritage, innovation, etc., and in these functions, the first is the talent cultivation, but also the most basic functions of the training And other functions of the logical starting point, at the same time, or modern colleges and universities and the fundamental tasks and mission of education. If a university will give up the task of personnel training, then, it is no longer called the university. After the statistics, today the scale of higher education in our country has reached as high as 36.47 million people, and higher education gross enrollment rate is as high as $40 \%$, and these are the future of the country, therefore, in education is not any mistakes.

Education is the most basic means, and higher education is not only an intermediate converter, the students from the family into social people, but also to promote the development of modern society of the engine, so that it has multiple social attributes. Higher education has multiple social attributes, can only show that it only adapt to the community, in order to healthy development, so that in order to bear their own social responsibility. The multiple social attributes in higher education include the social attributes of the superstructure, the social attributes of the productive forces and the social attributes of the culture. The social attributes of the superstructures are mainly the activities of cultivating talents, and the party's education policy is fully implemented. People, pay attention to the construction of the community, successors to train. The social attributes of productive forces are mainly the basic way to cultivate high-quality laborers. It can not only promote the development of science and technology, but also promote the social progress and improve the national competitiveness and the direct means. Cultural social attributes, education belongs to the cultural heritage, mainly through the knowledge to teach, application, creation of the transmission, and then let the social evolution of the evolution can be achieved. Through the above, have shown that higher education has the scientific, rational, professional thinking to lead the correct thinking of society responsibility.

Although higher education has multiple social attributes, but the most basic, the most fundamental or personnel training, which is its essential attributes. Although the current socialization, social needs can be met, but also need to socialize, personality to enhance self-improvement. Under the severe supervision of the 18th National Congress and the Higher Education Law, the primary task of higher education is to cultivate talents and carry out activities such as practical ability and social responsibility in the spirit of innovation ${ }^{[3]}$. Therefore, in the quality of students, physical aspects of the promotion should not only focus on the moment, but also to people-oriented thinking fully embodied, adhere to the Lide tree people, and, in the high-level professional training at the same time promote the comprehensive development of people.

For higher education, the quality is the lifeline, and the fundamental requirement of education development is education-oriented. Therefore, in the 21st century, the urgent need for national development is how to improve the quality of personnel training in colleges and universities, and strengthen the inherent requirements of colleges and universities.

\section{The new era of education work put forward new requirements - high quality}

With the scale of higher education in China, resulting in the world for our country are in a state of concern. Although the scale of education in China has made a leap-forward development, the popularity and the world scale have achieved the first breakthrough, but compared to some higher education power, is still in a backward state. At present, after the statistics, the employment rate of ordinary college graduates has been hovering around $70 \%$ for a long time, and it is not enough to supply top-notch talents and industrial technical skills talents in the development of national development, leading to higher education and social economy The development of the existence of a certain degree of incompatibility, which also led to the high quality of higher education personnel 
training there is a certain lack. Therefore, in order to be able to improve the quality of education work effectively, China's relevant departments to do a series of targeted measures, as follows.

The Ministry of Education, the Ministry of Finance in January 2007 jointly below, in the implementation of the "undergraduate teaching quality and teaching in colleges and universities, the Ministry of Education, the Ministry of Education, the Ministry of Education, the Ministry of Education, the Ministry of Education, "The 13th Five-Year Plan for National Economic and Social Development of the People's Republic of China" was published in March 2016, which clearly put forward the "improve quality, more equitable" thinking ${ }^{[4]}$. Through the above measures, the decision to make higher education into a new course, and determine the success or failure of the key is the quality of personnel training.

\section{Practice undergraduate construction path}

To make the "double first-class" construction is effective, then the concept of education must be updated, the reform of personnel training model, the construction of teachers, innovative teaching management system, the construction of university culture, and require colleges and universities to follow the law, , Long-term accumulation and other aspects of a breakthrough.

\section{Educational ideas update}

The success of the construction of first-class undergraduate education depends on the concept of innovation, that is, the concept of education and reform thinking. First of all, to make advanced education, education values to establish a complete, and promote the comprehensive development of students on the premise that the school can adhere to the student-oriented, full, all-round, the whole process of education work. At the same time, it is also required to follow the law in teaching, to carry out teaching work mainly to Germany tree, a comprehensive training of moral and intellectual development, so that high-quality undergraduate talent can more adapt to economic and social development needs. In addition, it is necessary to make the connotation of talent view and diversified quality view can be reconstructed. For the popularization of higher education and the characteristics of the popularization of the characteristics of the study, so that high-quality undergraduate talent and economic and social development more fit, and actively carry out diversified explore. Secondly, establish a modern teaching concept, practice "teaching students in accordance with their aptitude" teaching philosophy, to break the school's traditional education model. In this way, we should study the differences of students, to respect their options, to encourage the development of particular interests, as well as in personnel training and education and teaching system reform in the deepening [5]. In addition, in the teaching activities, should be in the past to teachers, teaching materials, classroom-centered teaching model out, into a student-centered modern teaching model, so that by transforming the role of teachers and students to learn to build a community, To the teaching, learning methods to explore new ways, so that learning results continue to improve, so that learning efficiency effectively improved. Finally, we should establish the correct concept of development. To improve the quality, efficiency can be improved, then it should be the focus of development to optimize the structure, will be the expansion of the impulse to exercise, adhere to the scale, structure, quality, efficiency, and maintain a reasonable pace of development. In addition, in the reform of undergraduate talent training model, as well as disciplines, teachers in the construction of the "bottleneck" problems encountered, weak links, we should seize the focus, focus on exploration, and then solve. At the same time, for the management of culture, the construction of campus culture need to give some attention. Therefore, through the long-term accumulation, continue to sublimate, cultivate undergraduate talent, the construction of school professional, cultural, so that school characteristics gradually formed in sharp contrast, so that first-class university and first-class discipline development more effective. 


\section{Reform and deepen the undergraduate talent training mode}

Personnel training mode in a broad sense, mainly include the content of personnel training goals and specifications, professional settings and construction, curriculum system and teaching content, teaching methods and teaching methods, teaching evaluation and quality control, which covers the intrinsic elements of talent Training objectives, content, methods, conditions. So, to make the school into a "double first-class" undergraduate education, not only need students with comprehensive development capabilities, to adapt to the needs of economic and social needs, but also must abide by the laws of education and teaching, the school's characteristics of the principle of full play, So that the advanced personnel training model and quality assurance system to explore the construction of meaningful ${ }^{[6]}$. Therefore, in view of the above, colleges and universities should not only to the economic and social development, scientific and technological progress, the transformation of educational development and personnel training reform and other aspects of the serious challenges facing serious and in-depth study, but also need to effectively promote innovation and entrepreneurship education , The subject of professional structure optimization and adjustment, the education mechanism coordination and improvement, which can further promote the training of top-notch entrepreneurship, information technology, education and teaching depth of integration, so that undergraduate education and teaching reform more clearly.

1.Talent goals, specifications training to establish. With the development of the times, economic and social, science and technology, higher education is also followed the pace, especially undergraduate education, its education system has formed a variety of personnel training type. Therefore, we must clear the talent of academic, application-oriented, technical goals, and then training. According to the "Higher Education Law" in the basic teaching standards of undergraduate education, in-depth study, refine the professional knowledge, ability, quality training requirements and specifications.

2.The establishment of a disciplinary professional system. Professional system in the establishment, to clear it is an important platform for the training of talent, then, in the set, must have a scientific standardization, professional access, adjustment, exit mechanism, combined with systematic, forward-looking, practical update, adjustment Professional connotation. In addition, the discipline construction and professional development between the complementary, mutual promotion of dialectical relations properly handled, so that professional integration and discipline construction to promote.

3.Teaching content and curriculum system optimization, training ability. Through the overall optimization of student knowledge structure, curriculum system point of view to theory and practice, knowledge and professional, subject professional foundation and vocational skills training balance. At the same time, attention to develop students' independent thinking ability, problem awareness, critical spirit, and the ability to analyze and solve problems so that teaching practice and vocational skills training time to be reasonable arrangements to enable students to improve their practical ability.

4. Learn from international experience, improve the internal quality assurance system, teaching reform methods, means, science and education into education, is also "double first" in the construction of important content, indispensable. Learn from the experience of foreign undergraduate education to protect the education system in undergraduate education in China, so that in fact the teaching methods, means of reform, rational and scientific integration into education and teaching, so that the "double first-class" Show, make it more effective.

\section{Conclusion}

In short, to make "double first-class" construction can be carried out smoothly, not only need to integrate with the current social economy and society, while colleges and universities also need to have the ability to bear many responsibilities, in-depth reform of personnel training model, reconstruction teaching management mechanism, System, and create a campus culture, teaching 
atmosphere, so that in order to enable higher education to promote and promote national economic and social development.

\section{References}

[1] Ma Luting. Undergraduate Education Cannot Be Missed in "Double first-class" Construction, Chinese University Teaching, 2016 (05): 09.

[2] Yu Bin, Jia Yaqiong, Xie Wei, et. Reflection on the Project of Undergraduates' Innovation in Local Undergraduate Colleges in the Background of "Double First-class" - Taking Hunan University of Technology as an Example, 2017 (01): 07.

[3] Zhong Binglin, Fang Fang. The Important Connotation of First-class Undergraduate Education in "Double first-class" Construction of, Chinese University teaching, 2016 (04): 4.

[4] Zhang Chunping. First-class discipline construction to help the first-class undergraduate education - Beijing Industrial and Commercial University President Sun Baoguo academician interview, Higher Education Development Research, 2016 (10): 27.

[5] Huang Jin. World-class university construction and first-class undergraduate teaching innovation - the Concept and Practice for China University of Political Science and Law, China Higher Education Research 2016 (06): 11.

[6] Lin Huiqing. First-class university to run first-class undergraduate education, Domestic higher education teaching research, 2016 (17): 1. 